\title{
Nickel removal by biosorption onto medlar male flowers coupled with photocatalysis on the spinel $\mathrm{ZnMn}_{2} \mathrm{O}_{4}$
}

\author{
Ahmed Chergui ${ }^{1}$, Farid Madjene ${ }^{2 *}$, Mohamed Trari $^{2}$ and Ali Khouider ${ }^{1}$
}

\begin{abstract}
$\mathrm{Ni}^{2+}$ is a highly toxic above $0.07 \mathrm{mg} / \mathrm{L}$ and its removal is of high significance. The biosorption of $\mathrm{Ni}^{2+}$ onto medlar male flowers (MMF) was studied in relation with the physical parameters like $\mathrm{pH}$, contact time, biosorbent dosage, $\mathrm{Ni}^{2+}$ concentration and temperature. The interaction biosorbent- $\mathrm{Ni}^{2+}$ was examined by the FTIR technique. The equilibrium was achieved within $40 \mathrm{~min}$ and the data were well fitted by the Langmuir and Redlich-Peterson (R-P) models. The maximum $\mathrm{Ni}^{2+}$ uptake capacity was $17.073 \mathrm{mg} / \mathrm{g}$ at $25^{\circ} \mathrm{C}$ and the $\mathrm{Ni}^{2+}$ removal follows a pseudo-second order kinetic with activation energy of $13.3 \mathrm{~kJ} / \mathrm{mol}$. The thermodynamic parameters: $\Delta S^{\circ}, \Delta H^{\circ}$ and $\Delta G^{\circ}$ showed that the biosorption was spontaneous and endothermic. MMF was used as a post treatment technique and the biosorption was coupled with the visible light driven $\mathrm{Ni}^{2+}$ reduction over the spinel $\mathrm{ZnMn}_{2} \mathrm{O}_{4}$. The effect of the $\mathrm{pH}, \mathrm{ZnMn}_{2} \mathrm{O}_{4}$ loading and light intensity on the photoactivity was investigated. $77.5 \%$ of $\mathrm{Ni}^{2+}$ was reduced after $\sim 140$ min under optimal conditions. The $\mathrm{Ni}^{2+}$ removal reached a rate conversion of $96 \%$ of with the coupled system biosorption/photocatalysis is very promising for the water treatment.
\end{abstract}

Keywords: Biosorption, Nickel, Medlar male flower, Photocatalytic

\section{Introduction}

Extensive industrial activities have led to tremendous increase in the use of toxic metals over the last decades provoking large scale pollution. Soil and water were continuously contaminated by heavy metals coming from various industries. $\mathrm{Ni}^{2+}$ cannot be biodegraded unlike organic pollutants; it persists indefinitely and accumulates through the food chain, thus posing a serious threat to human health [1]. Nickel is known as one of the most common toxic metals and inhaled nickel compounds are carcinogenic and provoke asthma, chronic bronchitis, pulmonary embolism as well as respiratory and may bring nausea, dizziness and diarrhea [2,3]. The WHO has drastically reduced at $0.07 \mathrm{mg} / \mathrm{L}$ the authorized threshold for nickel in drinking water [4]. Therefore, it was necessary to treat metal-contaminated water prior its discharge in the aquatic environment. Several techniques

\footnotetext{
* Correspondence: faridmadjene@hotmail.fr

${ }^{2}$ Laboratory of Storage and Valorization of Renewable Energies, Faculty of Chemistry, Algiers, Algeria

Full list of author information is available at the end of the article
}

have been used to this end, like precipitation, ion exchange, biosorption and membranes [5]. In recent years, considerable attention has been focused on the biosorption using agricultural materials [6,7]. Hence, efforts were done to develop inexpensive biosorbents using agricultural wastes. We have tested several biological materials for the metals removal and studies were carried out to investigate the potential of locally available biosorbent namely the medlar male flowers (MMF) for the nickel removal from aqueous solutions. The contact time, biosorbent dose, $\mathrm{pH}, \mathrm{Ni}^{2+}$ concentration and temperature were optimized. To understand the nature of the $\mathrm{Ni}^{2+}$ biosorption on MMF, equilibrium isotherms were analyzed by the Freundlich, Langmuir and Redlich-Peterson (R-P) models. Kinetic and thermodynamic parameters were also evaluated.

On the other hand, the biosorption greatly reduces the pollution but often not enough to comply with the standards of the world health organization. At this level, the photocatalysis appears to be quite promising because

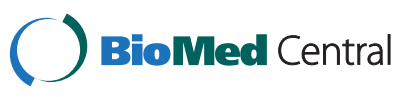


of its simplicity. There were only few studies on the combined systems (biosorption/photocatalysis) for the water treatment. So, in a second step, the system was directed to the spinel photocatalyst $\mathrm{ZnMn}_{2} \mathrm{O}_{4}$ which was presented as having the required photoelectrochemical parameters. Its conduction band $(\mathrm{CB})$ derives from $3 d$ orbital able to reduce metal ions to the elemental states. In addition, it is low cost, non-toxic and chemically stable under the operating conditions.

\section{Experimental}

MMF obtained from local farms (Algiers) is thoroughly washed with water and dried at $80^{\circ} \mathrm{C}$. Then, it was crushed, ground in an agate mortar and sieved to select a particle size of $500 \mu \mathrm{m}$ by using an ASTM standard sieve. It was stored in closed bottles until use.

The $\mathrm{Ni}^{2+}$ stock solution $(1 \mathrm{~g} / \mathrm{L})$ was prepared by dissolving the accurate quantity of $\mathrm{NiSO}_{4}, 6 \mathrm{H}_{2} \mathrm{O}$ (Merck, 99\%) in distilled water. Concentrations down to $50 \mathrm{mg} / \mathrm{L}$ were prepared by dilution. The $\mathrm{pH}$ was adjusted to the desired value by addition $\mathrm{HCl}$ or $\mathrm{NaOH}$ using a digital $\mathrm{pH}$ meter (Schott 825). The batch experiments were done in a double walled Pyrex reactor of $500 \mathrm{~cm}^{3}$ capacity (Figure 1) whose temperature was regulated by a thermostated bath (Julabo) under magnetic stirring (500 rpm). This was achieved to investigate the optimal conditions of $\mathrm{pH}(2-7)$, biosorbent dosage (3-9 g/L), $\mathrm{Ni}^{2+}$ concentrations $(50-250 \mathrm{mg} / \mathrm{L})$ and temperature $\left(15-55^{\circ} \mathrm{C}\right)$. The aliquots were withdrawn at regular time intervals and filtered off. The supernatant was analyzed for residual $\mathrm{Ni}^{2+}$ concentration with a double beam UV-Visible spectrophotometer (Shimadzu 1800). The solution was mixed to dimethylglyoxime in presence of bromine in ammoniacal medium and the complex was titrated at $465 \mathrm{~nm}$. The turbidity was measured using an Aqualytic turbidimeter (WTW Turb 550). The amount of
$\mathrm{Ni}^{2+}$ uptake and the biosorption percentage were calculated from the relations:

$$
\begin{aligned}
& q=\left(C_{o}-C\right) \frac{V}{m_{s}} \\
& (\%)=\frac{C_{o}-C}{C_{o}} \times 100
\end{aligned}
$$

The FTIR spectra of unloaded and $\mathrm{Ni}^{2+}$ loaded MMF were recorded on an infrared spectrometer (Jasco-3200) using the $\mathrm{KBr}$ routine technique. The specific surface area was measured by the BET method with a Quadrasorb SI apparatus (Micromeritics ASAP 2010). The point of zero charge (pzc) was determined by the immersion technique described elsewhere [8].

The spinel $\mathrm{ZnMn}_{2} \mathrm{O}_{4}$ was synthesized by sol-gel. A stochiometric mixture of $\mathrm{Zn}\left(\mathrm{NO}_{3}\right)_{2}, 6 \mathrm{H}_{2} \mathrm{O} / \mathrm{Mn}\left(\mathrm{NO}_{3}\right)_{2}$, $6 \mathrm{H}_{2} \mathrm{O}(0.025 \mathrm{M} / 0.05 \mathrm{M})$, both of purity greater than $99 \%$, was dissolved in $60 \mathrm{~mL}$ of ethylene glycol at room temperature. The solution was heated under stirring at $70^{\circ} \mathrm{C}(6 \mathrm{~h})$ under reflux and the viscous solution was dried at $120^{\circ} \mathrm{C}$. The amorphous powder was heated at $850^{\circ} \mathrm{C}$ and furnace cooled. The phase was confirmed by $\mathrm{X}$-ray diffraction (XRD) using monochromatized $\mathrm{Cu} \mathrm{K \alpha}$ radiation. The photocatalytic tests were carried out in the same reactor (Figure 1). The light source was a $200 \mathrm{~W}$ tungsten lamp (Osram) disposed at $10 \mathrm{~cm}$ above the reactor. The light flux was measured with a commercial light meter (roline RO 1332). The light was turned on after a transition period of $2 \mathrm{~h}$ for the dark adsorption onto the spinel.

\section{Results and discussion}

Characterization of the biosorbent

The physical characteristics of MMF were summarized in Table 1 . The FTIR spectra of unloaded and $\mathrm{Ni}^{2+}$-loaded

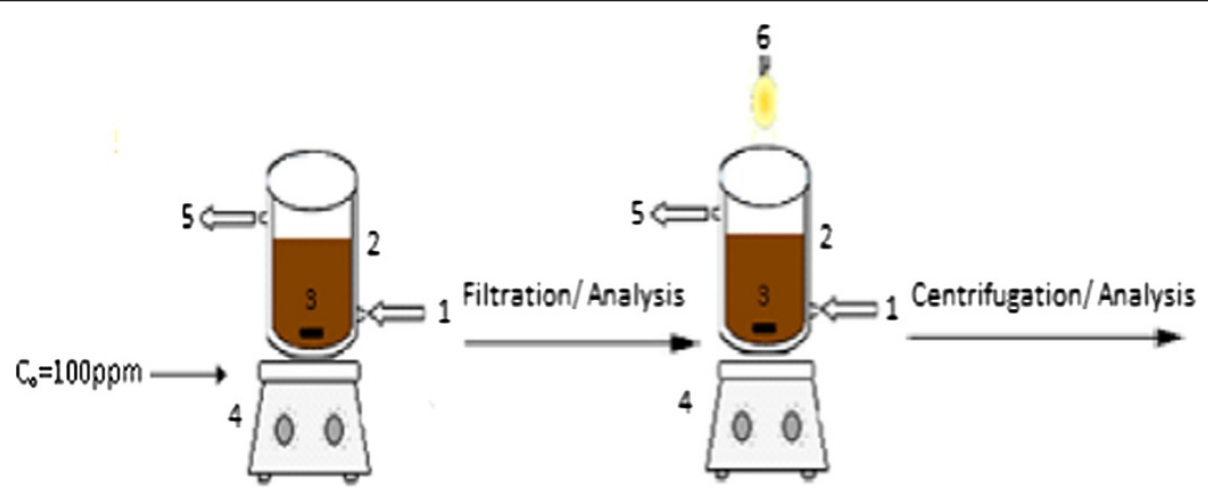

1: Water inlet; 2: Double walled reactor; 3: Stir bar;

4: Magnetic stirrer; 5: Water outlet; 6: Tungsten lamp.

Figure $1 \mathrm{~A}$ schematic diagram of the coupled biosorption/photocatalysis system. 
Table 1 Physico-chemical characterization of the MMF

Parameters

Particle size (mm)

0.5

BET surface area $\left(\mathrm{m}^{2} / \mathrm{g}\right)$

2.78

$\mathrm{pH}_{\mathrm{PZC}}$

7.26

MMF (Figure 2) were compared to get insights on the nature of the biosorbent- $\mathrm{Ni}^{2+}$ interactions and to determine the frequency changes in the functional groups for $\mathrm{Ni}^{2+}$ binding. The spectrum of MMF shows a strong band at $3444 \mathrm{~cm}^{-1}$ attributed to hydroxyl groups. The peak at $2920 \mathrm{~cm}^{-1}$ is due to the $\mathrm{C}-\mathrm{H}$ stretching frequency whereas that at $1644 \mathrm{~cm}^{-1}$ is assigned to $\mathrm{C}=\mathrm{O}$ stretching of the primary and secondary amides $\left(\mathrm{NH}_{2} \mathrm{CO}\right)$. The peaks at 1505 and $1382 \mathrm{~cm}^{-1}$ are due to $\mathrm{N}-\mathrm{H}$ stretching of primary and secondary amides, and amide (III) respectively. Bands at 1320 and $1243 \mathrm{~cm}^{-1}$ are characteristic of carboxylic acids. The strong $\mathrm{C}-\mathrm{O}$ band at $1057 \mathrm{~cm}^{-1}$ confirms the lignin structure of MMF [9]. The FTIR spectrum of $\mathrm{Ni}^{2+}$ loaded MMF (Figure 2b) shows a decrease in intensity and a shift in asymmetric stretching frequencies at 3444, 1644 and $1505 \mathrm{~cm}^{-1}$ due to coordinated $\mathrm{Ni}^{2+}$ ions by hydroxyl, carboxyl, and amides groups respectively on the MMF surface.

\section{Effect of contact time}

The effect of the contact time on the rate of $\mathrm{Ni}^{2+}$ removal is shown in Figure 3. The process was rapid at the beginning due to large surface area of the biosorbent and gradually decreases to reach an equilibrium state. The plots reveal that the maximum percentage of $\mathrm{Ni}^{2+}$ removal occurs after $40 \mathrm{~min}$ of shaking. Then, the biosorption becomes controlled by the rate of $\mathrm{Ni}^{2+}$ transported to internal sites of the grains.

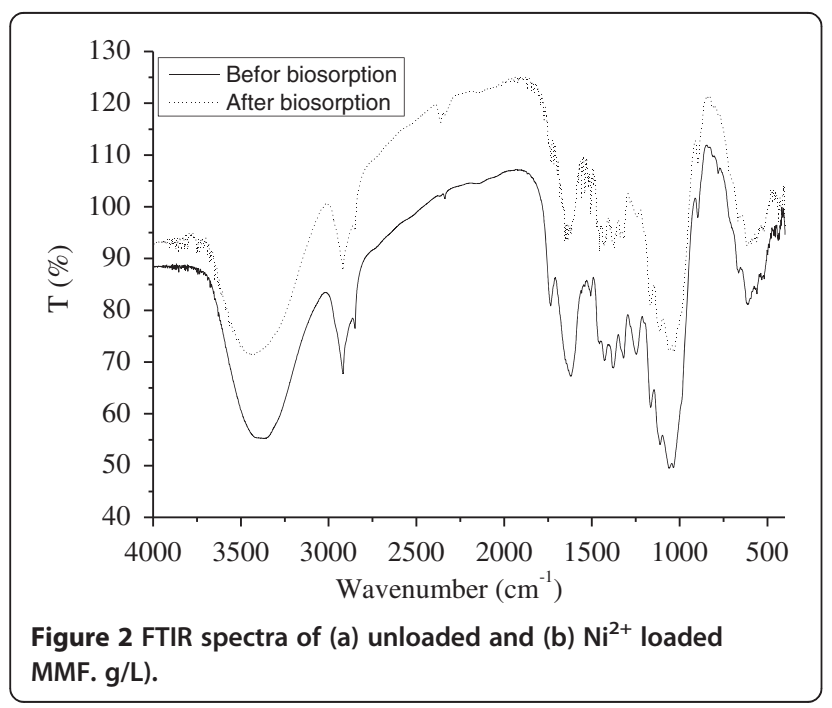

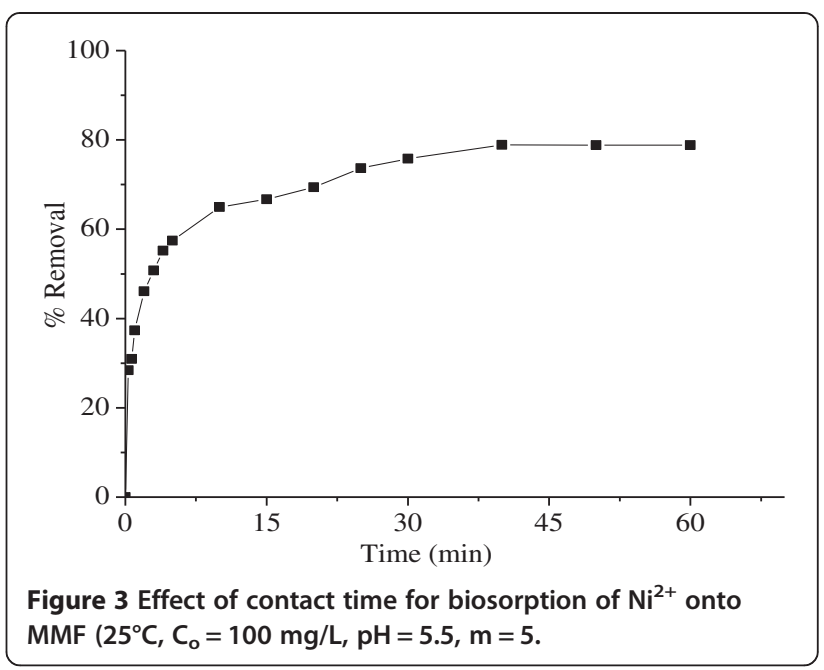

\section{Effect of the biosorbent dose}

As expected, the $\mathrm{Ni}^{2+}$ biosorption increases with increasing the MMF dose, and becomes almost constant beyond $7 \mathrm{~g} / \mathrm{L}$ (Figure 4). With increasing the MMF dose, more surface area is available due to increasing number of active sites, thus making easier the penetration of $\mathrm{Ni}^{2+}$ to the biosorption sites. So, we have used a biosorbent dose of $7 \mathrm{~g} / \mathrm{L}$ for the following experiments. Further increase of the mass does not produce a significant effect on the $\mathrm{Ni}^{2+}$ biosorption because of the saturation effect. This new biosorbent could not only remove $\mathrm{Ni}^{2+}$, but also produces a weak turbidity not exceeding $1.73 \mathrm{NTU}$ which an acceptable value. It is worthwhile to outline that a low turbidity is an important requirement for the water treatment.

The $\mathrm{pH}$ is an important parameter for controlling the biosorption and its influence on the $\mathrm{Ni}^{2+}$ uptake by MMF is illustrated in Figure 5. Experiments were done by varying the $\mathrm{pH}$ over the range $(2-7)$ at $25^{\circ} \mathrm{C}$ with

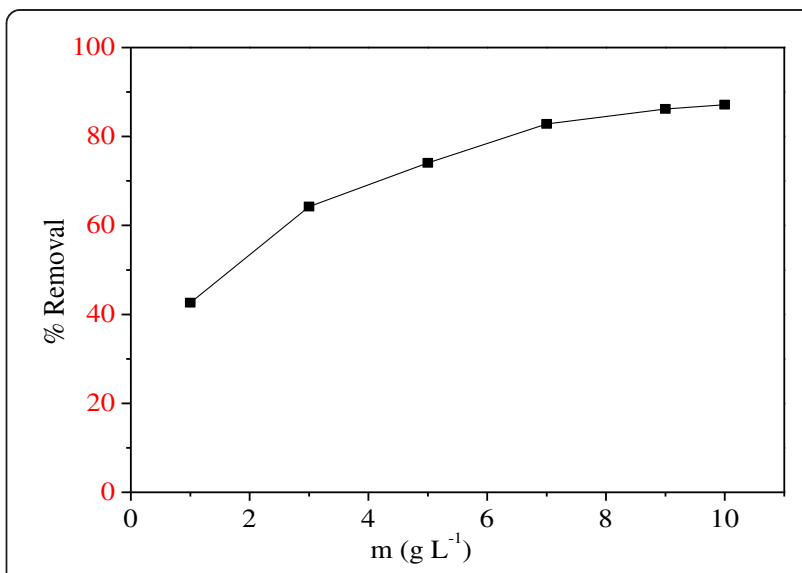

Figure 4 Effect of biosorbent dose for $\mathrm{Ni}^{2+}$ biosorption onto $\operatorname{MMF}\left(25^{\circ} \mathrm{C}, \mathrm{t}=40 \mathrm{~min}, \mathrm{C}_{\mathrm{o}}=100 \mathrm{mg} / \mathrm{L}, \mathrm{pH}=5.5\right)$. 


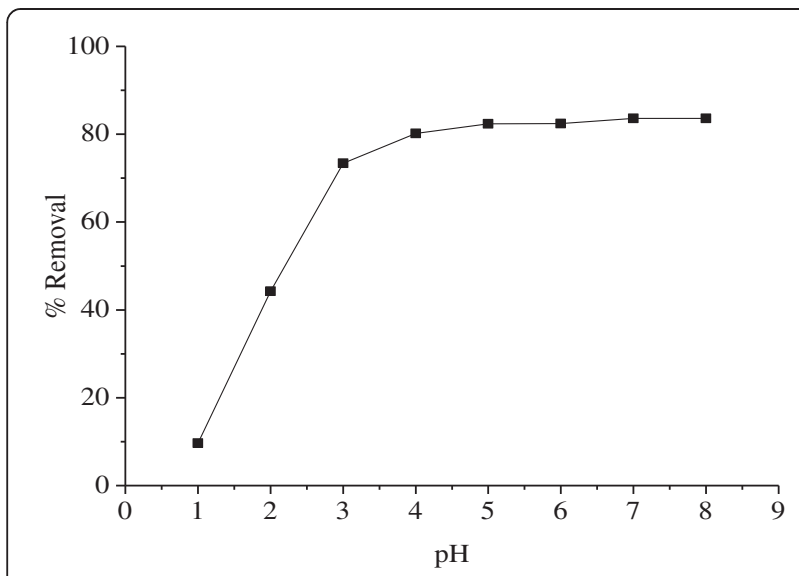

Figure $5 \mathrm{Effect}$ of $\mathrm{pH}$ for $\mathrm{Ni}^{2+}$ biosorption onto $\mathrm{MMF}\left(25^{\circ} \mathrm{C}\right.$, $\mathrm{t}=40 \mathrm{~min}, \mathrm{C}_{\mathrm{o}}=100 \mathrm{mg} / \mathrm{L}, \mathrm{m}=7 \mathrm{~g} / \mathrm{L}$ ).

MMF dose of $7 \mathrm{~g} / \mathrm{L}$. The performance increases rapidly with increasing $\mathrm{pH}$ up to 5 , then slowly and beyond $\mathrm{pH} 8.5, \mathrm{Ni}(\mathrm{OH})_{2}$ precipitates owing to the low solubility product $\left(\sim 10^{-16}\right)$. At acidic pHs, the MMF surface is covered by $\mathrm{H}^{+}$ions and $\mathrm{Ni}^{2+}$ cannot compete for biosorption sites. The increase in the biosorption at higher $\mathrm{pHs}$ is likely associated with deprotonation of the biosorbent surface or other negatively charged groups lead to electrostatic attraction of $\mathrm{Ni}^{2+}$ ions. Based on these results, the best biosorption occurs at $\mathrm{pH} \sim 7$ with a percentage removal of $83 \%$. Accordingly, the further biosorption studies are carried around this $\mathrm{pH}$ which is close to the real $\mathrm{pH}$ of naturel medium.

\section{Effect of temperature}

The thermal variation of the $\mathrm{Ni}^{2+}$ uptake at a concentration of $100 \mathrm{mg} / \mathrm{L}$ onto MMF is shown in Figure 6. An increase of the temperature results in an enhanced biosorption rate and the maximum uptake occurs at $40^{\circ} \mathrm{C}$.

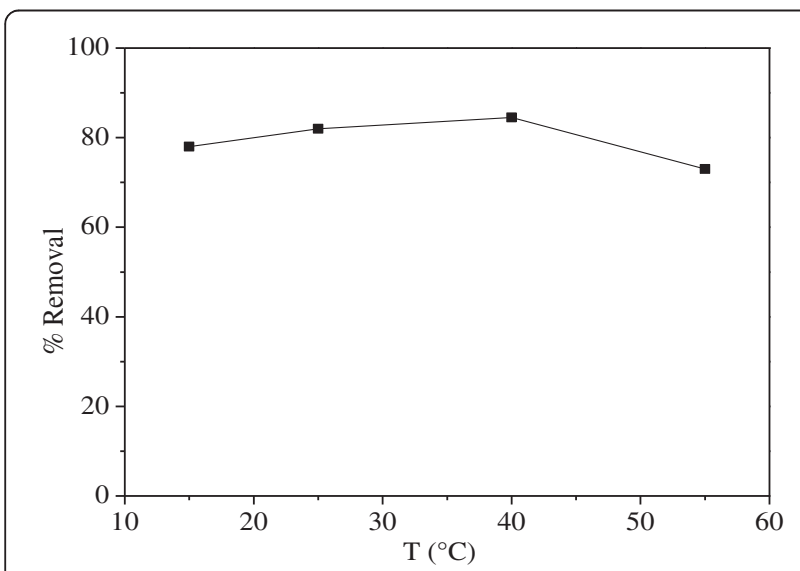

Figure 6 Effect of temperature for $\mathrm{Ni}^{2+}$ biosorption onto MMF $\left(C_{o}=100 \mathrm{mg} / \mathrm{L}, \mathrm{t}=40 \mathrm{~min}, \mathrm{pH}=5.5, \mathrm{~m}=7 \mathrm{~g} / \mathrm{L}\right)$.

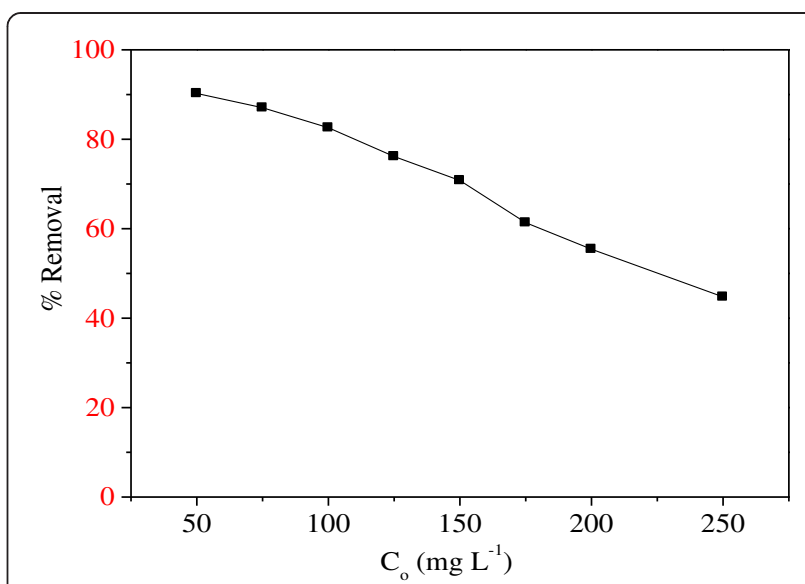

Figure 7 Effect of $\mathrm{Ni}^{2+}$ concentration for biosorption onto MMF $\left(25^{\circ} \mathrm{C}, \mathrm{t}=40 \mathrm{~min}, \mathrm{pH}=5.5, \mathrm{~m}=7 \mathrm{~g} / \mathrm{L}\right)$.

At that temperature, an increasing number of molecules acquire sufficient energy to interact with active sites. Furthermore, raising temperature produces a swelling effect within the internal MMF structure, thus enabling large amount of $\mathrm{Ni}^{2+}$ ions to access to inside cavities.

The $\mathrm{Ni}^{2+}$ removal, evaluated for the biosorption isotherms, clearly indicates an endothermic process. However, the biosorption was found to decrease at higher temperatures $\left(55^{\circ} \mathrm{C}\right)$ possibly due to the damage of active binding sites in the biomass. In addition, the water vaporization becomes an increasing problem. Nevertheless, the temperature-dependence is somewhat different in our case, and this may be due to the differences in the experimental conditions and the nature of the biosorbent. As a result, the temperature of $40^{\circ} \mathrm{C}$ is found to be optimal. However, the $\mathrm{Ni}^{2+}$ biosorption at $40^{\circ} \mathrm{C}(84 \%)$ is close to that at $25^{\circ} \mathrm{C}(82 \%)$. So, to save energy the last temperature is selected for further experiments.

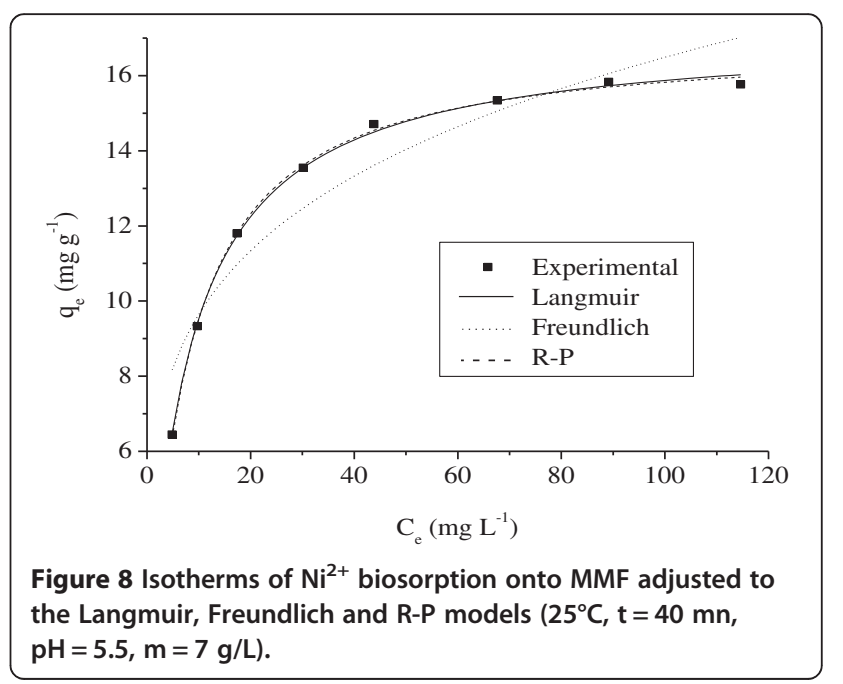


Table 2 The isotherm constants for the $\mathrm{Ni}^{2+}$ biosorption onto MMF under optimized conditions for Langmuir Freundlich and Redlich-Peterson models

\begin{tabular}{cccccccccc}
\hline & Langmuir & \multicolumn{3}{c}{ Freundlich } & \multicolumn{4}{c}{ Redlich-Peterson } \\
\hline $\mathrm{q}_{\mathrm{m}}$ & $\mathrm{b}$ & $\mathrm{R}^{2}$ & $\mathrm{~N}$ & $\mathrm{~K}_{\mathrm{f}}$ & $\mathrm{R}^{2}$ & $\mathrm{~K}_{\mathrm{R}}$ & $\mathrm{a}_{\mathrm{R}}$ & $\mathrm{g}$ & $\mathrm{R}^{2}$ \\
17.143 & 0.125 & 0.9984 & 0.232 & 5.650 & 0.9054 & 1.996 & 0.104 & 1.024 & 0.9990 \\
\hline
\end{tabular}

\section{Effect of initial concentration}

Nickel comes from industrial activities and discharged in the aquatic medium at concentration up to $400 \mathrm{mg} / \mathrm{L}$. So it is interesting to study the effect of concentration. The equilibrium $\mathrm{Ni}^{2+}$ uptake for different concentrations $(50-250 \mathrm{mg} / \mathrm{L})$ at $25^{\circ} \mathrm{C}$ on $\operatorname{MMF}(7 \mathrm{~g} / \mathrm{L})$ at $\mathrm{pH} \sim 7$ is shown in Figure 7. The biosorption rate decreases with increasing $\mathrm{Ni}^{2+}$ concentration from $83 \%(50 \mathrm{mg} / \mathrm{L})$ to $62 \%(250 \mathrm{mg} / \mathrm{L})$. At low $\mathrm{Ni}^{2+}$ concentrations, the binding sites are unsaturated and consequently available for the biosorption process. By contrast, for high $\mathrm{Ni}^{2+}$ concentrations the number of ions competing for the available sites on the biomass increases, thus resulting in a decrease of the $\mathrm{Ni}^{2+}$ biosorption.

\section{Biosorption isotherms}

The analysis of the isotherm by fitting the experimental data to various models is an important step for the design purpose. Three models are tested namely the Langmuir, Freundlich and Redlich-Peterson (R-P) ones. a) The Langmuir model is successfully used for homogenous biosorption surface [2]:

$$
q_{e}=\frac{q_{m} b C_{e}}{1+b C_{e}}
$$

Figure 8 illustrates the plots at $25^{\circ} \mathrm{C}$, the constants $\mathrm{q}_{\mathrm{m}}$ and $\mathrm{b}$ are gathered in Table 2 .

The high coefficients $\mathrm{R}^{2}$ show that the $\mathrm{Ni}^{2+}$ biosorption onto MMF follows the Langmuir model whose main feature is expressed in term of a dimensionless separation constant $\left(\mathrm{R}_{\mathrm{L}}\right)[10]$ :

$$
R_{L}=\frac{1}{1+b C_{o}}
$$

The $\mathrm{R}_{\mathrm{L}}$ value indicates the type of isotherm: unfavorable $\left(R_{L}>1\right)$, linear $\left(R_{L}=1\right)$, favorable $\left(0<R_{L}<1\right)$ or irreversible $\left(R_{L}=0\right)$ [10]. The $R_{L}$ values for different $\mathrm{Ni}^{2+}$ concentrations are given in Table 3 . It can be observed

Table 3 The separation factor versus the initial $\mathbf{N i}^{2+}$ concentration

\begin{tabular}{lccccccc}
\hline $\begin{array}{l}\mathrm{C}_{\mathrm{o}} \\
(\mathrm{mg} / \mathrm{L})\end{array}$ & 40 & 60 & 80 & 100 & 150 & 200 & 250 \\
\hline $\mathrm{R}_{\mathrm{L}}$ & 0.0868 & 0.0596 & 0.0454 & 0.0366 & 0.0247 & 0.0186 & 0.0150 \\
\hline
\end{tabular}

that $\mathrm{R}_{\mathrm{L}}$ lies in the range $0-1$ in all experiments, thus confirming the favorable $\mathrm{Ni}^{2+}$ uptake onto MMF.

The maximum biosorption capacity $\left(\mathrm{q}_{\mathrm{m}}\right)$ is compared with other biosorbents reported in the literature (Table 4), where $\mathrm{q}_{\mathrm{m}}$ has not been derived specifically. One can see that the maximum $\mathrm{Ni}^{2+}$ biosorption capacity is intermediate compared to other biosorbents and MMF is a promising for the water treatment. b) The Freundlich model is suitable for heterogeneous surfaces [11]:

$$
q_{e}=K_{f} C_{e}^{1 / n}
$$

Figure 8 shows the plots while the constants $K_{\mathrm{f}}$ and $1 / \mathrm{n}$ are given in Table 2 . The values of $1 / n$, less than 1 , indicating a favorable biosorption. However, the theoretical values deviate from the experimental data suggesting that the model is not appropriate to describe the $\mathrm{Ni}^{2+}$ biosorption onto MMF.

c) The R-P model combines both the Langmuir and Freundlich ones and the hybrid mechanism does not follow a monolayer biosorption [14]:

$$
q_{e}=\frac{K_{R} C_{e}}{1+a_{R} C_{e}^{g}}
$$

The exponent $g$ varies between 0 and 1 . It is helpful to outline that for $g=1$, the equation converts simply to the Langmuir isotherm while for $g=0$, it is simplified to the Henry's law. For $1<<a_{R} \cdot C_{e}^{g}$, the model is identical to the Freundlich one. Table 2 lists the biosorption parameters together with the $\mathrm{R}^{2}$ values. A comparison between the theoretical and experimental data of $\mathrm{Ni}^{2+}$ biosorption onto MMF was well illustrated in Figure 8. The R-P equation applied over the whole concentrations range gives a coefficient $R^{2}$ close to 1 , thus

Table 4 Biosorption capacities of different biosorbents for $\mathrm{Ni}^{2+}$ removal from water

\begin{tabular}{lcc}
\hline Biosorbent & $\mathbf{q}_{\mathbf{m}}(\mathbf{m g} \mathbf{g})$ & Ref. \\
\hline Gracilaria caudata & $\mathbf{4 5}$ & {$[2]$} \\
Sargassum muticum & $\mathbf{7 0}$ & {$[2]$} \\
Tea factory waste & 15.2 & {$[3]$} \\
Activated sludge & $\mathbf{2 3 8 . 1}$ & {$[5]$} \\
Baker's yeast & $\mathbf{8 . 2}$ & {$[12]$} \\
Aspergillus niger & $\mathbf{4 . 8 2}$ & {$[13]$} \\
Medlar male flower & $\mathbf{1 7}$ & This study \\
\hline
\end{tabular}



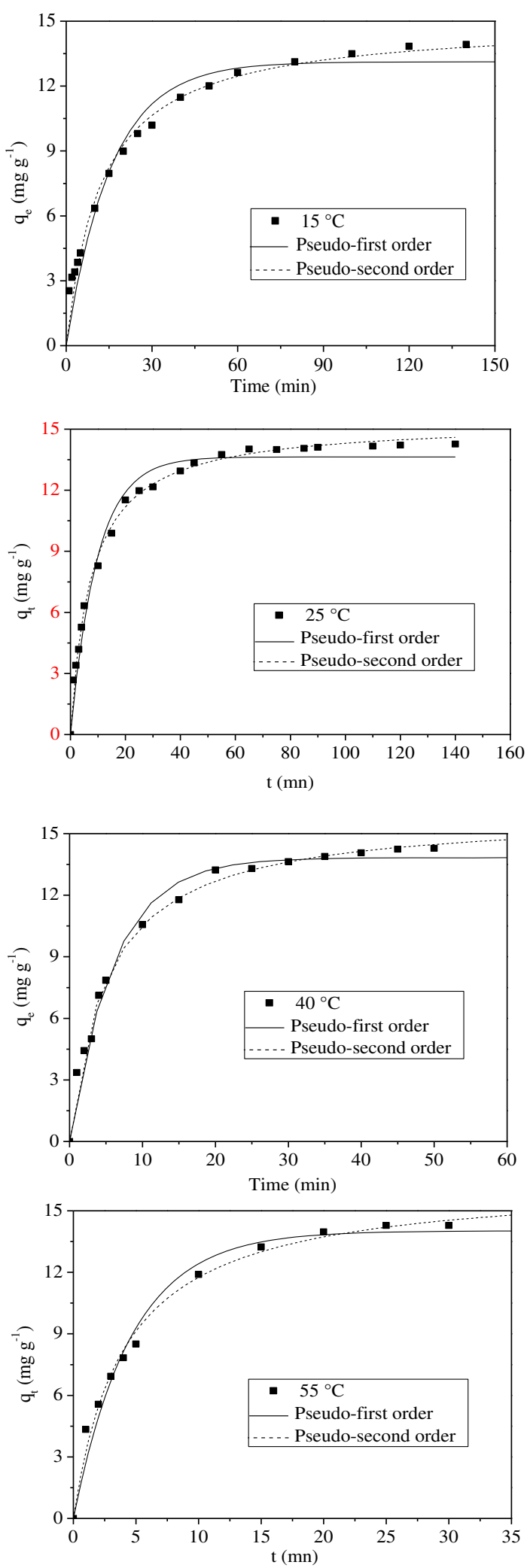

Figure 9 Biosorption kinetics plot of $\mathrm{Ni}^{2+}$ onto MMF biomass. confirming the best fit for $\mathrm{Ni}^{2+}$ biosorption for the two models. The g values were close to unity and this means that the isotherm approaches the Langmuir model rather than the Freundlich one. Hence, the good fit of the equilibrium data for Langmuir and R-P isotherms confirms the monolayer coverage of $\mathrm{Ni}^{2+}$ onto MMF.

\section{Biosorption kinetic}

The biosorption kinetic is important from a practical point of view since it controls the efficiency of the process and the models correlate the $\mathrm{Ni}^{2+}$ uptake rate with the bulk concentration. In order to analyze the biosorption rate, the kinetic data were modeled with the Lagergren pseudo-first-order and pseudo-second order equations [15].

$$
\begin{aligned}
& \text { Pseudo-first-order : } q_{t}=q_{e}\left(1-e^{-k_{1} t}\right) \\
& \text { Pseudo-second-order : } q_{t}=q_{e} \frac{q_{e} k_{2} t}{1+q_{e} k_{2} t}
\end{aligned}
$$

where $\mathrm{q}_{\mathrm{t}}$ and $\mathrm{q}_{\mathrm{e}}$ are the amounts of $\mathrm{Ni}^{2+}$ adsorbed $(\mathrm{mg} / \mathrm{g})$ at time $(\mathrm{t})$ and at equilibrium, respectively, $\mathrm{k}_{1}\left(\mathrm{~min}^{-1}\right)$ and $\mathrm{k}_{2}$ ( $\mathrm{mg} / \mathrm{g} \mathrm{min}$ ) are the corresponding rate constants. $\mathrm{q}_{\mathrm{t}}, \mathrm{k}_{1}$, and $k_{2}$ were calculated by the non-linear regression analysis (Figure 9) using the Origin program (version 7.5). The optimization uses the error function to fit the experimental data.

The coefficients $R^{2}$ and the chi-square test $\left(\chi^{2}\right)$ were used to measure the goodness-of-fit:

$$
\chi^{2}=\sum_{i=1}^{N} \frac{\left(q_{e}-q_{i}\right)}{q_{i}}
$$

where $q_{e}$ is the observation from the batch experiment, $q_{i}$ the estimate from the isotherm for corresponding $\mathrm{q}_{\mathrm{e}}$ and $\mathrm{N}$ the number of observations in the experimental isotherm. If the data from the model are similar to the experimental ones, $X^{2}$ is small [16]. The coefficients $R^{2}$ and $X^{2}$ in the temperature range $\left(15-55^{\circ} \mathrm{C}\right)$ indicate that the biosorption kinetic was well described by the pseudosecond-order equation (Table 5). The comparison of the experimental and theoretical values of $\mathrm{q}_{\mathrm{t}}$ evaluated from

\begin{tabular}{|c|c|c|c|c|c|c|}
\hline \multirow[t]{3}{*}{$\mathrm{T}(\mathrm{K})$} & \multicolumn{3}{|c|}{ Pseudo-first-order } & \multicolumn{3}{|c|}{ Pseudo-second-order } \\
\hline & $k_{1}$ & $x^{2}$ & $R^{2}$ & $k_{2}$ & $x^{2} \times 10^{3}$ & $\mathrm{R}^{2}$ \\
\hline & $\overline{\left(\min ^{-1}\right)}$ & & & $\begin{array}{c}(\mathrm{g} / \\
\mathrm{mg} \min )\end{array}$ & & \\
\hline 288 & 0.0634 & 0.2113 & 0.9599 & 0.1327 & 3.056 & 0.9880 \\
\hline 298 & 0.1006 & 0.2711 & 0.9425 & 0.1536 & 0.566 & 0.9863 \\
\hline 313 & 0.1641 & 0.1769 & 0.9315 & 0.2499 & 0.762 & 0.9800 \\
\hline 328 & 0.2169 & 0.8849 & 0.9770 & 0.2987 & 0.025 & 0.9938 \\
\hline
\end{tabular}

Table 5 Kinetic parameters for $\mathrm{Ni}^{2+}$ biosorption onto MMF at different temperatures 
Table 6 Thermodynamic parameters for the biosorption of $\mathrm{Ni}^{2+}$ onto MMF at different temperatures

\begin{tabular}{cccc}
\hline $\mathrm{T}(\mathrm{K})$ & $\begin{array}{c}\Delta \mathrm{G}^{\circ} \\
(\mathrm{kJ} / \mathrm{mol})\end{array}$ & $\begin{array}{c}\Delta \mathrm{H}^{\circ} \\
(\mathrm{kJ} / \mathrm{mol})\end{array}$ & $\begin{array}{c}\Delta \mathrm{S}^{\circ} \\
(\mathrm{J} / \mathrm{mol} \mathrm{K})\end{array}$ \\
\hline 288 & -3.460 & & \\
298 & -3.921 & 9.806 & 46.065 \\
313 & -4.612 & & \\
328 & -5.303 & & \\
\hline
\end{tabular}

Eq. (8) shows that for all temperatures, $\mathrm{q}_{t}$ is almost constant and increases with temperature along with $\mathrm{k}_{2}$.

\section{Thermodynamic parameters of biosorption}

The free energy $\left(\Delta G^{\circ}\right)$ of the biosorption is related to the equilibrium constant $\left(\mathrm{k}_{\mathrm{c}}\right)$ by [3]:

$$
\Delta \mathrm{G}=-R T \ln k_{c}=\Delta H-T \Delta S, \quad k_{c}=\frac{C_{o}-C_{e}}{C_{e}}
$$

The standard enthalpy $\left(\Delta H^{\circ}\right)$ and entropy $\left(\Delta \mathrm{S}^{\circ}\right)$ were obtained from the linear plot $\operatorname{lnk}_{\mathrm{c}}$ versus $1 / \mathrm{T}$. The negative value of $\Delta G^{\circ}$ (Table 6) indicates a spontaneous biosorption and the low temperatures make the biosorption easier. The positive values of $\Delta \mathrm{H}^{\circ}$ and $\Delta \mathrm{S}^{\circ}$ implies that the $\mathrm{Ni}^{2+}$ biosorption onto MMF was endothermic with increased randomness at the solid/solution interface.

\section{Photocatalytic process}

As mentioned above, the $\mathrm{Ni}^{2+}$ uptake on MMF greatly reduces the pollution but not sufficiently to comply with the standards of the water quality. However, the biosorption can be used as post treatment for the photocatalyic process. Using colloidal semiconductor particles as light absorbing units is simple and does not need any sophisticated device. The first step was to generate electron/

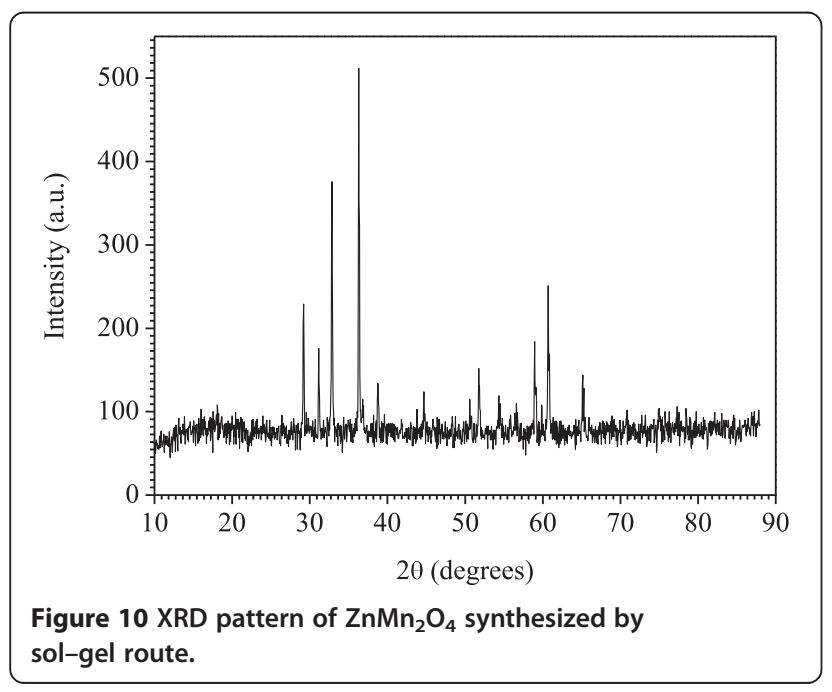

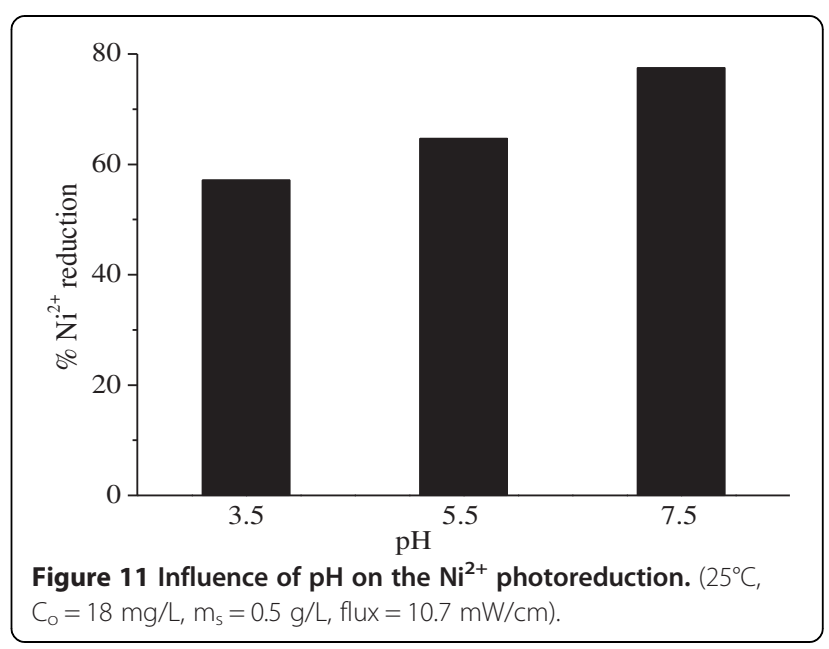

hole $\left(\mathrm{e}^{-} / \mathrm{h}^{+}\right)$pairs on a semiconductor by energetic photons $(\mathrm{h} v>\mathrm{Eg}) . \mathrm{Ni}^{2+}$ was photo-electrochemically reduced to elemental state. In this respect, the spinel $\mathrm{ZnMn}_{2} \mathrm{O}_{4}$ shows light absorption for wavelengths shorter than $730 \mathrm{~nm}$. In addition, the oxide is chemically stable and has been elaborated via sol-gel route in order to increase the active surface.

Even though the photocatalytic processes are related to the morphology of the material, a detailed understanding of the fundamental properties is required to get a highquality powder. $\mathrm{ZnMn}_{2} \mathrm{O}_{4}$ was synthesized by sol-gel and the XRD pattern (Figure 10) is characteristic of single phase. All peaks are assigned to the spinel phase in agreement with the JCPDS card $\mathrm{N}^{\circ}$ 24-1133. Nevertheless, when the calcination temperature exceeds $850^{\circ} \mathrm{C}$, the crystallites can agglomerate in grains and decrease the specific surface area. This has been corroborated by the lack of XRD peak broadening and the relatively small active surface $\left(28 \mathrm{~m}^{2} / \mathrm{g}\right)$.

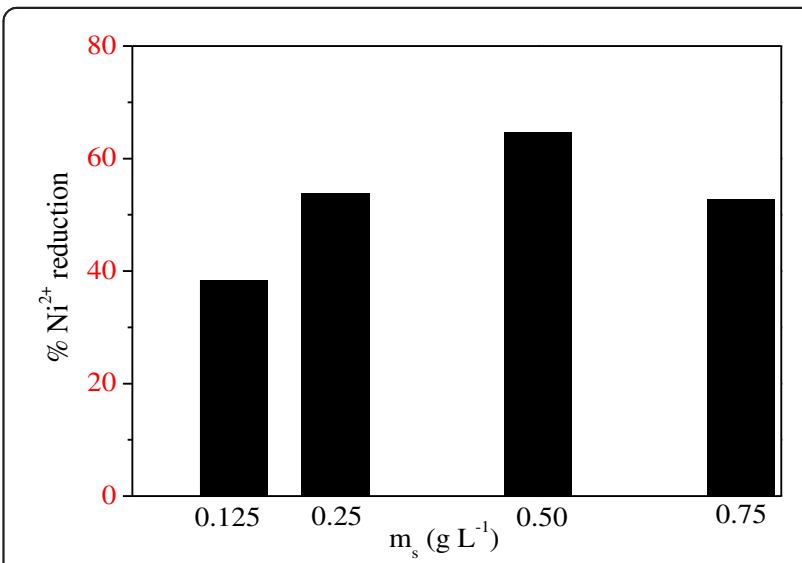

Figure 12 Influence of the mass of $\mathrm{ZnMn}_{2} \mathrm{O}_{4}$ on the $\mathrm{Ni}^{2+}$ photoreduction $\left(25^{\circ} \mathrm{C}, \mathrm{C}_{\mathrm{o}}=18 \mathrm{mg} / \mathrm{L}, \mathrm{pH}=7.5\right.$, light flux $=10.7 \mathrm{~mW} / \mathrm{cm}$ ). 


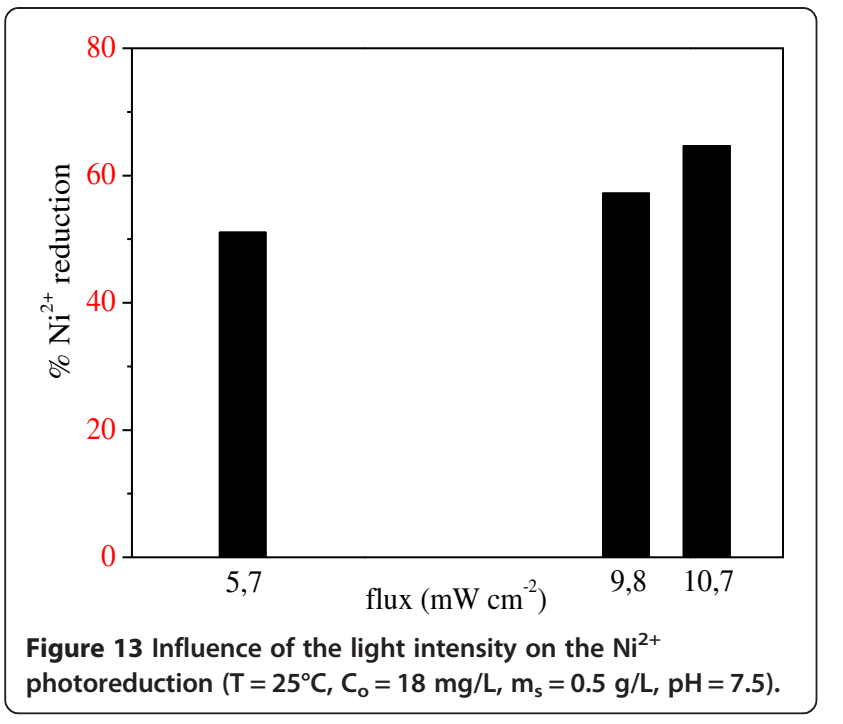

The main interest of this section was to investigate the effect of some physical parameters on the $\mathrm{Ni}^{2+}$ photoreduction. A transition period is required before irradiation and the suspension $\mathrm{ZnMn}_{2} \mathrm{O}_{4}$ was maintained in the dark during this period. The starting concentration was set at $18 \mathrm{ppm}$ and the $\mathrm{Ni}^{2+}$ solution was equilibrated with the catalyst during $2 \mathrm{~h}$ to establish the adsorption conditions. The difference between the nominal concentration and that of measured after equilibrium was taken as the quantity of adsorbed $\mathrm{Ni}^{2+}$ onto $\mathrm{ZnMn}_{2} \mathrm{O}_{4}(\sim 5 \%)$. The $\mathrm{pH}$ of the solution has a direct influence on the photo-electrodeposition via the surface charge catalyst. With $\mathrm{Ni}^{2+}$, the adsorption follows a cationic type law and is pronounced at high $\mathrm{pH}$. We have conducted the experiments for $140 \mathrm{~min}$ at different $\mathrm{pHs}$ and the corresponding fractional reduction of $\mathrm{Ni}^{2+}$ is presented in Figure 11. It appears that the photoreduction was maximum ( 77.5\%) at $\mathrm{pH} 7.5$ and decreased rapidly with decreasing $\mathrm{pH}$, in acidic media, the $\mathrm{Ni}^{2+}$ were repelled by the positive surface charge of $\mathrm{ZnMn}_{2} \mathrm{O}_{4}$. In the $\mathrm{pH}$ range (3.5-7.5) the photocatalytic $\mathrm{Ni}^{2+}$ reduction on $\mathrm{ZnMn}_{2} \mathrm{O}_{4}$ was rather limited.

The photocatalytic tests were carried out with various amounts of $\mathrm{ZnMn}_{2} \mathrm{O}_{4}$ and the rate of $\mathrm{Ni}^{2+}$ reduction increases with increasing the mass of $\mathrm{ZnMn}_{2} \mathrm{O}_{4}$ (Figure 12). For smaller doses, less actives sites for the reduction process are available and the photoactivity increases in parallel with the amount of $\mathrm{ZnMn}_{2} \mathrm{O}_{4}$. On the contrary, for higher doses, all photocatalytic sites are saturated and the light scattering of the incident flux, the shadowing effect of the powder catalyst; the metal clusters account for the decrease of the activity.

Indeed, the incident light on the metal surface was partially absorbed and converted to heat. The two opposing effects gave an optimal $\mathrm{ZnMn}_{2} \mathrm{O}_{4}$ dose of $0.5 \mathrm{~g} / \mathrm{L}$. Increasing light intensity enhanced both the rate and the extent of $\mathrm{Ni}^{2+}$ reduction (Figure 13).

Taking into account the adsorption and the photoreduction, the modified Langmuir-Hinshelwood model was successfully applied to assess the $\mathrm{Ni}^{2+}$ photoreduction rate [17].

$$
\frac{-d C}{d t}=k_{a p p} C_{o}
$$

The reaction occurs between adsorbed species on the spinel surface. The linear plot of $\ln C / C_{o}$ vs time indicates that the reduction obeys to a first order kinetic

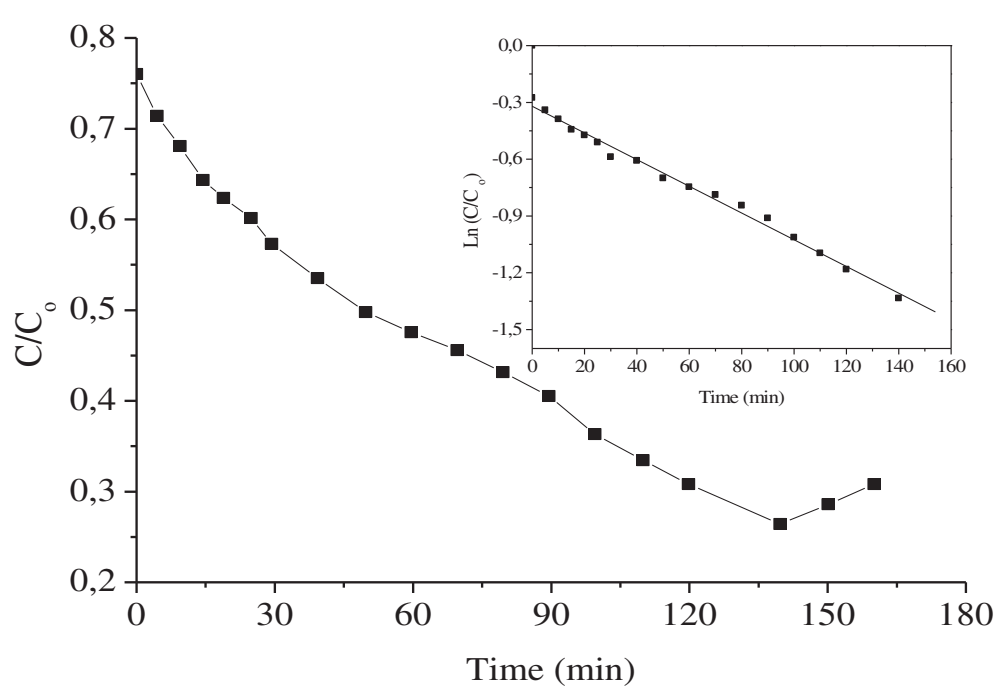

Figure 14 Photoreduction of $\mathrm{Ni}^{2+}$ on $\mathrm{ZnMn}_{2} \mathrm{O}_{4}$. Inset: The plot of $\mathrm{Ln} C / \mathrm{C}_{0}$ Vs. time. 
(Figure 14). The apparent reaction constant $\left(\mathrm{k}_{\mathrm{app}}\right)$ averages $0.42 \mathrm{~h}^{-1}$ and the half life, i.e. the time needed for the concentration to fall to half of its initial value, was found to be concentration independent and averages $1.5 \mathrm{~h}$.

\section{Conclusion}

An agricultural by product namely the Medlar male flower, locally available has been successfully used for $\mathrm{Ni}^{2+}$ biosorption from aqueous solution. The contact time, biosorbent dose, $\mathrm{pH}$ and temperature were optimized. The maximum biosorption capacity was obtained at $\mathrm{pH} 5$, and the equilibrium was reached in less than $40 \mathrm{~min}$. The isotherms data were well fitted with both the Langmuir and Redlich-Peterson models. The negative free energy confirmed a favorable $\mathrm{Ni}^{2+}$ biosorption where the positive enthalpy indicated an endothermic nature. The spinel $\mathrm{ZnMn}_{2} \mathrm{O}_{4}$ elaborated by co-precipitation, was used to reduce the remaining concentration by photocatalysis into elemental state. A reduction rate of $77.5 \%$ was achieved after $2 \mathrm{~h}$ irradiation at $\mathrm{pH} 7.5$ with an optimal $\mathrm{ZnMn}_{2} \mathrm{O}_{4}$ mass equal to $0.5 \mathrm{~g} / \mathrm{L}$. The photoreduction followed a first order kinetic. The results indicated that the coupled system may be a viable alternative and a new way for the $\mathrm{Ni}^{2+}$ removal in aquatic medium.

\section{Nomenclature}

b Langmuir biosorption constant ( $\mathrm{L} / \mathrm{mg})$

$\mathrm{C}_{\mathrm{e}}$ Residual $\mathrm{Ni}^{2+}$ concentration at equilibrium $(\mathrm{mg} / \mathrm{L})$

$\mathrm{C}_{\mathrm{o}}$ Initial $\mathrm{Ni}^{2+}$ concentration $(\mathrm{mg} / \mathrm{L})$

Eg The optical gap

$K_{f}$ The Freundlich constants denoting the biosorption capacity $\left(\mathrm{mg}^{1-1 / \mathrm{n}} / \mathrm{g} \mathrm{L}^{1 / \mathrm{n}}\right)$

$\mathrm{k}_{1}$ Pseudo-first order biosorption rate constant $\left(\mathrm{min}^{-1}\right)$

$k_{2}$ Pseudo-second order biosorption rate constant

(g/mg min)

$k_{\text {app }}$ The apparent reaction constant

$\mathrm{k}_{\mathrm{c}}$ Standard thermodynamic equilibrium constant.

$k_{\text {app }}$ The apparent reaction constant

$\mathrm{m}$ Biosorbent dosage (g)

$\mathrm{m}_{\mathrm{s}}$ semiconducteur dosage $(\mathrm{g})$

$\mathrm{n}$ The Freundlich constants denoting the biosorption intensity

$\mathrm{q}_{\mathrm{e}}$ Amount of $\mathrm{Ni}^{2+}$ adsorbed on the biosorbent at equilibrium $(\mathrm{mg} / \mathrm{g})$

$\mathrm{q}_{\max }$ Langmuir biosorption constant (mg/g)

$\mathrm{q}_{\mathrm{t}}$ Amount of $\mathrm{Ni}^{2+}$ adsorbed on the sorbent at any

time $(\mathrm{mg} / \mathrm{g})$

$\mathrm{R}$ Universal gas constant

$\mathrm{R}^{2}$ Correlation coefficient

$\mathrm{R}_{\mathrm{L}}$ Dimensionless separation factor

$\mathrm{T}$ Absolute temperature (K)

$\mathrm{t}$ Time of biosorption (min)
$\Delta G^{\circ}$ Free energy $(\mathrm{kJ} / \mathrm{mol})$

$\Delta \mathrm{H}^{\circ}$ Enthalpy change $(\mathrm{kJ} / \mathrm{mol})$

$\Delta \mathrm{S}^{\circ}$ Entropy change $(\mathrm{J} / \mathrm{mol} \mathrm{K})$

\section{Competing interests}

All authors declare that they have no competing interest.

\section{Authors' contributions}

AC and FM were the main authors, designed and performed the study and drafted the manuscript. MT supervised the work. AK helped in the biosorption study. All authors read and approved the final manuscript.

\section{Acknowledgments}

The authors are grateful to Dr Nabila Nedjari for technical assistance in the FTIR measurements. This research is financially supported by the Faculty of Chemistry (USTHB, Algiers).

\section{Author details}

${ }^{1}$ Laboratory of Electrochemistry-Corrosion, Metallurgy and Inorganic Chemistry, Faculty of Chemistry, Algiers, Algeria. ${ }^{2}$ Laboratory of Storage and Valorization of Renewable Energies, Faculty of Chemistry, Algiers, Algeria.

Received: 4 September 2012 Accepted: 15 October 2013

Published: 8 January 2014

\section{References}

1. Lopez A, Lazaro N, Morales S, Marques AM: Nickel biosorption by free and immobilized cells of pseudomonas fluorescens 4F39: a comparative study. Water Air and Soil Pollutio. 2002, 135:157-172(16).

2. Bermúdez YG, Rico ILR, Bermúdez OG, Guibal E: Nickel biosorption using gracilaria caudata and sargassummuticum. Chem Eng J 2011, 166:122-131.

3. Malkoc E, Nuhoglu Y: Investigations of nickel(II) removal from aqueous solutions using tea factory waste. J Hazard Mater 2005, 127:120-128.

4. WHO: Nickel in drinking-water. Background document for development of WHO guidelines for drinking-water quality. 4th edition. Geneva, Switzerland: World Health Organization; 2011.

5. Aksu Z, Acıkel U, Kabasakal E, Tezer S: Equilibrium modeling of individual and simultaneous biosorption of chromium(VI) and nickel(II) onto dried activated sludge. Water Res 2002, 36:3063-3073.

6. Subbaiah MV, Vijaya Y, Reddy AS, Yuvaraja G, Krishnaiah A: Equilibrium, kinetic and thermodynamic studies on the biosorption of $\mathrm{Cu}$ (II) onto trametes versicolor biomass. Desalination 2011, 276:310-316.

7. Vinodhini V, Das N: Packed bed column studies on $\mathrm{Cr}(\mathrm{VI})$ removal from tannery wastewater by neem sawdust. Desalination 2010, 264:9-14.

8. Faria PCC, Órfão JJM, Pereira MFR: Adsorption of anionic and cationic dyes on activated carbons with different surface chemistries. Water Res 2004, 38:2043-2052.

9. PascoalNeto C, Rocha J, Gil A, Cordeiro N, Esculcas AP, Rocha S, Delgadillo I, Pedrosade Jesus JD, FerrerCorreia AJ: 13 C solid-state nuclear magnetic resonance and Fourier transform infrared studies of the thermal decomposition of cork. Solid State Nud Mag 1995, 4:143-151.

10. Ncibi MC, Mahjoub B, Ben Hamissa AM, Ben Mansour R, Seffen M: Biosorption of textile metal-complexed dye from aqueous medium using posidonia oceanica (L.) leaf sheaths: mathematical modeling. Desalination 2009, 243:109-121.

11. Chakravarty P, SenSarma N, Sarma HP: Removal of lead(II) from aqueous solution using heartwood of areca catechu powder. Desalination 2010, 256:16-21.

12. Padmavathy $\mathrm{V}$ : Biosorption of nickel(II) ions by baker's yeast: Kinetic, thermodynamic and desorption studies. Bioresour Technol 2008, 99:3100-3109.

13. Amini M, Younesi $H$, Bahramifar $N$ : Biosorption of nickel(II) from aqueous solution by Aspergillus Niger: response surface methodology and isotherm study. Chemosphere 2009, 75:1483-1491.

14. Anirudhan TS, Jalajamony S, Suchithra PS: Improved performance of a cellulose-based anion exchanger with tertiary amine functionality for the adsorption of chromium(VI) from aqueous solutions. Colloids Surf $A$ Physicochem Eng Asp 2009, 335:107-113. 
15. Kurniawan A, Sisnanda VOA, Trilestari K, Sunarsb J, Indraswata N, Ismadji S: Performance of durian shell waste as high capacity biosorbent for $\mathrm{Cr}(\mathrm{VI})$ removal from synthetic wastewater. Ecol Eng 2011, 37:940-947.

16. Ho YS, Chiu WT, Wang CC: Regression analysis for the sorption isotherms of basic dyes on sugarcane dust. Bioresour Technol 2005, 96:1285-1291.

17. Brahimi R, Bessekhouad $Y$, Nasrallah $\mathrm{N}$, Trari M: Visible light $\mathrm{CrO}_{4}{ }^{2-}$ reduction using the new $\mathrm{CuAlO2/CdS}$ hetero-system. $J$ Hazard Mater 2012, 219-220:19-25.

doi:10.1186/2052-336X-12-13

Cite this article as: Chergui et al:: Nickel removal by biosorption onto medlar male flowers coupled with photocatalysis on the spinel $\mathrm{ZnMn}_{2} \mathrm{O}_{4}$. Journal of Environmental Health Science \& Engineering 2014 12:13.

\section{Submit your next manuscript to BioMed Central and take full advantage of:}

- Convenient online submission

- Thorough peer review

- No space constraints or color figure charges

- Immediate publication on acceptance

- Inclusion in PubMed, CAS, Scopus and Google Scholar

- Research which is freely available for redistribution 